\title{
LOS DESÓRDENES DEL CANÓNIGO DE LA CATEDRAL DE ORIHUELA JOSÉ LLOP. REFORMA, DELITOS Y CASTIGO EN EL SIGLO XVII ${ }^{1}$
}

\section{The disorders of José Llop, canon of the Oribuela's cathedral. Reform, crimes and punishment in the $17^{\text {th }}$ century}

\author{
Emilio CALLADO ESTELA \\ Universidad CEU - Cardenal Herrera \\ ecallado@uchceu.es
}

Fecha de recepción: 16/03/2019

Fecha de aceptación: 12/04/2019

RESUMEN: El presente artículo analiza los sucesos ocurridos en Orihuela durante el último tercio del siglo XVII con ocasión de los delitos atribuidos al canónigo José Llop, maleante contumaz de desordenada vida cuyo castigo dejó la mitra en manos del banco regio para consternación del cabildo de aquella diócesis, que reclamó para sí esta causa con el respaldo de otros capítulos catedralicios e incluso de la Congregación de las Iglesias de Castilla y León. Hasta la Santa Sede intervino en este asunto, con demasiadas implicaciones en el debate que sobre la inmunidad eclesiástica venía sustanciándose a lo largo y ancho del orbe católico.

Palabras clave: reforma; delitos; castigo; Iglesia; Orihuela; siglo XVII.

1. Este trabajo forma parte del Proyecto de Investigación La Catedral Barroca. Iglesia, sociedad y cultura en la Valencia del siglo XVII, financiado por el Ministerio de Economía, Industria y Competitividad del Gobierno de España (HAR2016-74907-R).

Ediciones Universidad de Salamanca / అ@@ Stud. his., H. ${ }^{a}$ mod., 42, n. 1 (2020), pp. 329-349 
EMILIO CALLADO ESTELA

LOS DESÓRDENES DEL CANÓNIGO DE LA CATEDRAL DE ORIHUELA JOSÉ LLOP. REFORMA, DELITOS Y CASTIGO EN EL SIGLO XVII

ABSTRACT: This article analyzes the events that occurred in Orihuela at the end of the 17 th century. Its protagonist, the canon José Llop, delinquent of disorderly life. The bishop left its punishment to the crown. But the cathedral chapter claimed this judicial cause with the support of other clergy and even of the Congregation of the Churches of Castilla y Leon. The Holy See also intervened because the repercussions of this matter in the general debate on ecclesiastical immunity.

Keywords: reformation; crimes; punishment; Church; Orihuela; 17th century.

Nadie cuestiona en la actualidad el impacto que la crisis del siglo XVII supuso para la trayectoria social y política del reino de Valencia (Casey, 1983). Demasiado a menudo se olvida, por el contrario, que tampoco a ésta lograría sustraerse la Iglesia local, inmersa en una de las peores coyunturas de toda su historia. A ella contribuyeron las resistencias internas a la reforma de Trento, cuya aplicación en las diócesis levantinas se había confiado al episcopado fundamentalmente, a través de sínodos, visitas canónicas y otros mandatos pastorales ${ }^{2}$. Ninguno de tales instrumentos bastó para enderezar al clero secular conforme al nuevo espíritu conciliar. Desde luego, no a los estratos bajos. Aunque tampoco a los superiores, que como los cabildos catedralicios conformaron la principal oposición a los obispos ${ }^{3}$. El panorama descrito se agravaría aún más como consecuencia de la violencia extendida en estas latitudes, bajo la especie sobre todo de los bandos o parcialidades que aglutinaban a gran parte de la población ${ }^{4}$. Incluidos no pocos clérigos, hombres de escasa vocación religiosa, ávidos de pingües beneficios y de las ventajas inherentes al privilegium fori que les eximía de la justicia ordinaria, sin necesidad de renunciar a una vida mundana y poco honesta -cuando no abiertamente delictiva- que los diferentes tribunales eclesiásticos debían atender en teoría (Pérez, 1992; Candau, 1993). La pacificación del territorio, sin embargo, sirvió de coartada a la corona para cuestionar en estos casos la jurisdicción de la Iglesia, origen de infinitos encontronazos

2. Únicamente el caso de la sede valentina ha sido estudiado con profusión, por Callado, 2001; 2007; 2009; 2018a.

3. Sobre el seminario de pleitos constituido en esta época por las iglesias catedrales de la práctica totalidad de la Monarquía véanse los estudios pioneros de Cereceda, 1944; Marín, 1948; Goñi, 1975. Un actualizado estado de la cuestión hasta el año de su publicación, Díaz, 2010. Para el caso valenciano en concreto, Callado, 2019.

4. A propósito del bandolerismo y sin ánimo de exhaustividad, merecen citarse García Martínez, 1991; Casey, 1988; Felipo, 1988; Ferrero, 1985; Guía, 1980, 1984, 1994, 2002, 2003; Urzainqui, 2016.

Ediciones Universidad de Salamanca / 요 Stud. his., H. ${ }^{a}$ mod., 42, n. 1 (2020), pp. 329-349 
EMILIO CALLADO ESTELA

LOS DESÓRDENES DEL CANÓNIGO DE LA CATEDRAL DE ORIHUELA JOSÉ LLOP. REFORMA, DELITOS Y CASTIGO EN EL SIGLO XVII

entre ambas en un contexto general caracterizado por el reforzamiento del poder estatal (Callado, 2003).

Solo en ocasiones se impondría la colaboración de trono y altar para la represión de semejantes conductas, ya por la gravedad de las mismas o el compromiso con el orden público y la estabilidad por parte de las autoridades correspondientes. Paradigmático al respecto -por su trascendencia y repercusiones más allá del lugar de los hechos- fue lo ocurrido en Orihuela, durante el último tercio de la centuria y para afrontar los delitos del canónigo José Llop, maleante contumaz de desordenada vida cuyo castigo dejó la mitra en manos del banco regio. Para consternación en la presente ocasión del cabildo de aquella seo, que reclamó para sí esta causa con el respaldo de otros capítulos catedralicios e incluso de la Congregación de las Iglesias de Castilla y León. Hasta la Santa Sede intervino en este asunto, con demasiadas implicaciones en el debate que sobre la inmunidad eclesiástica venía sustanciándose a lo largo y ancho del orbe católico 5 .

\section{PRIMERAS BARRABASADAS DEL CANÓNIGO LLOP}

Desde el Quinientos había existido en la ciudad de Alicante una colonia de comerciantes franceses que, con el mediar del siglo XVII, experimentaría un considerable crecimiento (Girard, 1934: 128), aún a pesar de las guerras contra el Rey Sol libradas durante el reinado de Carlos II (García Martínez, 1991: 283-308). Arraigaron entonces importantes linajes, como los Vinyau, Subiela y Lostau, de origen bearnés; los Marbeuf de Bretaña; o los Loup -pronto Llop- marselleses (Montojo, 2008: 227; 2010a: 212; 2010b: 55). Esta última estirpe debió su asentamiento aquí a un tal Jacques, cuya red mercantil era en absoluto despreciable. De hecho, los clientes del susodicho se localizaban no sólo entre las mejores plazas del intercambio peninsular, sino también en Mallorca ${ }^{6}$. Vínculos tales reforzados casi siempre a través de lazos familiares. Sin ir más lejos, su hermano Bartolomé mercadeaba desde el Puerto de Santa María. El mismo Jacques se había casado con Francisca Bojoni, de la influyente comunidad genovesa local. También contrajo nupcias con Diamante Briosco, antes de obtener el privilegio de milicia con voto en cortes como reconocimiento a su posición social?

5. Todavía en 1820 se recordaría este episodio en las Cartas de don Roque Leal a un amigo suyo, sobre la representación del arzobispo de Valencia a las cortes, fecha a 20 de octubre de 1820. Madrid: 28-31, apología de las medidas eclesiásticas de las cortes durante la primera legislatura del Trienio (Revuelta, 1973: 2).

6. Entre ellos, el italiano Raimundo Lantery (Bibiloni, 1990: 214 y Bustos, 1983: 111-112).

7. En 1682 (Arqués, 1966: 57). 
EMILIO CALLADO ESTELA

LOS DESÓRDENES DEL CANÓNIGO DE LA CATEDRAL DE ORIHUELA JOSÉ LLOP REFORMA, DELITOS Y CASTIGO EN EL SIGLO XVII

Con esta segunda esposa hubo Jacques Llop una numerosa prole, de la cual interesa ahora José. Nada sabemos de su nacimiento e infancia. Sí que, a edad temprana, dejaría a sus hermanos los negocios familiares para incorporarse al clero secular como los hijos segundones de tantas sagas urbanas bienestantes (Sánchez, 2000: 31). No lo hizo, al igual que tales, en un destino menor. Todo lo contrario, ingresaría en la catedral orcelitana, sede episcopal segregada de Cartagena en 1564 por el papa Pío IV (Carrasco, 2001). Allí existían desde aquella fecha media docena de dignidades eclesiásticas así como dieciséis canonjías -sin incluir la asignada al Santo Oficio- una de las cuales recalaba en un tío materno de nuestro protagonista ${ }^{8}$. A ella quedó vinculado éste en calidad de coadjutor, es decir con derecho a suceder a su familiar en la prebenda una vez fallecido? ${ }^{9}$. No lo evitarían ni reservas tridentinas ni posteriores declaraciones apostólicas a propósito de tan controvertida figura canónica, que garantizaba a los cabildos un control endogámico en la gestión de vacantes capitulares recaídas con frecuencia en muchachos no aptos para el servicio del altar ${ }^{10}$.

Este debió de ser el caso del joven Llop, cuya vida licenciosa -siempre como diácono-se había iniciado con anterioridad a ocupar su canonicato en propiedad. Hasta el extremo que, ya en 1673, el entonces ordinario del lugar recurría a la corona incapaz de poner freno a las demasías de su subordinado, remiso a abandonar la diócesis tras sucesivos apercibimientos en este sentido. Lo era José Vergé, recio obispo reformista del Oratorio de San Felipe Neri ${ }^{11}$. A instancias suyas, el 12 de julio de aquel año la regente doña Mariana de Austria ordenaba al lugarteniente general del reino de Valencia don Vespasiano Gonzaga, conde de Paredes, la caza y captura del clérigo para su inmediato traslado a los presidios de Ibiza, que no debería dejar hasta nuevo aviso. El gobernador de Alicante llegó a prenderlo en esta ciudad a medianoche y en una casa de lenocinio, para escándalo de cuantos presenciaron el arresto. Con todo, no cumpliría la condena prevista el reo, que tras un breve paso

8. A falta de estudios concretos sobre el particular, la evolución y características de estas prebendas puede seguirse en Cárcel, 1989.

9. Archivo de la Corona de Aragón[=ACA]. Consejo de Aragón. Leg. 686, doc. 63/115.

10. El sacrosanto y ecuménico concilio de Trento. Traducido al idioma castellano por don Ignacio López de Ayala. Barcelona [1845], sesión XXV, cap. VII Probíbense los accesos y regresos de los beneficios. De qué modo, a quién y por qué causa se ha de dar coadjutor, 366-367. En relación al tema, Aldea, 1961; Irigoyen, 2000:49-64.

11. Valenciano de nacimiento, se había doctorado en Teología en el Estudi General, donde obtuvo y regentó varias cátedras y pavordías y ejerció como vicecanciller un tiempo (Felipo y Callado, 2016: 252-253). Ejercía desde 1666 como obispo de Orihuela, sede que rigió hasta su muerte en 1679 (Vidal, 1961: I, 274-ss). Fue un prolífico publicista de la Inmaculada Concepción, según confirman sus obras Cultus praeservationis Deiparae a peccato originali in primo instanti animationis y De possibilitate praeservativae redemptionis Deiparae a peccato originali (Ximeno, 1747-1749: II, 81-82).

Ediciones Universidad de Salamanca / @®@@ Stud. his., H. ${ }^{a}$ mod., 42, n. 1 (2020), pp. 329-349 
por las cárceles reales del lugar fue entregado a la justicia eclesiástica para embarcarlo rumbo a Italia, donde habría de purgar sus penas durante tres años. Al segundo ya imploraba la familia misericordia para él, tanto a la mitra como al monarca Carlos II, que confiando en su rehabilitación le levantó el destierro en septiembre de $1676^{12}$.

En el Puerto de Santa María -quizá con su tío Bartolomé- residió un tiempo José Llop. Suficiente para perpetrar de nuevo «tan enormes delitos» como la violación de una joven de corta edad. Hasta en dos ocasiones el obispo de Cádiz Juan Fernández de Isla volvió a desterrarlo, al norte de África esta vez y durante seis años. Pronto se repetirían las súplicas por parte de Jacques Llop, en la presente ocasión con el apoyo del cabildo de la catedral de Orihuela y a partir de 1679 ante Antonino Sánchez de Castellar, recién estrenado como diocesano ${ }^{13}$.

Para congraciarse con ambos, el prelado negoció con su homólogo hispalense el traslado del coadjutor hasta la sede orcelitana, con el compromiso de hacérsele cumplir aquí su encierro sin regresar jamás a Andalucía. En efecto, nunca volvería Llop a pisar tierras del Guadalquivir. Pero cárcel ninguna, por cuanto eludió presentarse ante el ordinario de manera reiterada. Sánchez de Castellar intentó emprender nuevas acciones judiciales contra el clérigo, con el concurso de los dos jueces capitulares contemplados por Trento para el enjuiciamiento de prebendados ${ }^{14}$.

Si la catedral del lugar había constituido un remanso de paz hasta entonces -frente a otras en pie de guerra como consecuencia del reforzamiento de la autoridad episcopal por parte de los propios decretos conciliares- todo empezaría a cambiar desde este momento ${ }^{15}$. Porque ninguno de los canónigos se avino a los deseos del actual obispo. Al contrario, en un gesto de camaradería hacia el todavía coadjutor, le

12. ACA. Consejo de Aragón. Leg. 686, doc. 63/115.

13. Otro obispo orcelitano de Valencia, en cuya Universidad se doctoró en Teología antes de ordenarse sacerdote, ocuparse de la parroquia de San Pedro y ampliar estudios en la capital del Bajo Segura. En la catedral de esta última ciudad obtuvo la dignidad de arcediano de Alicante por intercesión del entonces ordinario José Vergé, del que fue estrecho colaborador y al que sustituyó a su muerte, tras dos provisiones frustradas de aquella mitra que ciñó hasta fallecer en 1700 (Vidal, 1961: I, 286-292).

14. «Establece el santo concilio que, en todas las iglesias catedrales y colegiatas se observe el decreto hecho en tiempo de Paulo II [...] que principia Cupitula cathedralium, no solo cuando visitare el obispo sino cuantas veces proceda de oficio o a petición de alguno contra alguna persona de las contenidas en dicho decreto. De suerte, no obstante, que cuando procediere fuera de visita tenga lugar todo lo que va a espresarse. Es a saber, que elija el cabildo, a principio de cada año, dos de sus capitulares, con cuyo parecer y asenso esté obligado a proceder el obispo o su vicario, tanto en la formación del proceso como en todos los demás actos hasta el fin inclusive de la causa». El sacrosanto y ecuménico concilio de Trento..., sesión XXV, cap. VI Cómo debe proceder el obispo en la visita de los cabildos esentos, 364.

15. A pesar de algunas afirmaciones, según las cuales «el señor Sánchez de Castellar no uvo pleito alguno [...] con su cabildo catedral» (Vidal, 1961: I, 290).

Ediciones Universidad de Salamanca / @®@@ Stud. his., H. ${ }^{a}$ mod., 42, n. 1 (2020), pp. 329-349 
EMILIO CALLADO ESTELA

LOS DESÓRDENES DEL CANÓNIGO DE LA CATEDRAL DE ORIHUELA JOSÉ LLOP REFORMA, DELITOS Y CASTIGO EN EL SIGLO XVII

otorgaron la titularidad de su canonjía, vacante desde hacía una década ${ }^{16}$. Dieron así más alas a la díscola vida de su compañero, que entregado a toda suerte de desmanes en Alicante, Orihuela y Murcia apenas atendería las obligaciones inherentes a su nueva condición. Hubo esta vez acuerdo entre mitra y conjudices para procesársele, aunque in extremis y con una leve condena de destierro impuesta por éstos últimos que de absolutamente nada serviría, como el tiempo no tardó en confirmar ${ }^{17}$.

\section{DEL ESCÁNDALO CON LAS MONJAS DE LA SANGRE}

A comienzos de 1681 nuestro clérigo protagonizaba un nuevo escándalo, ahora con las agustinas del convento alicantino de la Sangre bajo jurisdicción episcopal (Echániz, 2017). El cenobio en cuestión era contiguo a la casa de Jacques Llop, desde cuya terraza su hijo José galanteaba a las religiosas en compañía de su hermano menor Pompeyo, también eclesiástico, beneficiado en este caso. Tales devociones profanas -inocentes y castos parloteos casi siempre- atestaban los locutorios monjiles de la Monarquía, motivo por el cual venían siendo combatidas tanto por parte de la Iglesia como de la corona (D’Aulnoy, s.a.: 85; Domínguez, 1973: 330-331; Torremocha, 2007: 169-200). Ambas se habían empeñado a fondo en el cumplimiento del último breve apostólico de Alejandro VII sobre esta materia, puesto ahora en entredicho por los jóvenes Llop ${ }^{18}$.

Mientras el obispo de Orihuela denunciaba el caso ante Carlos II, el nombre del principal encausado se vería implicado en varias reyertas nocturnas, todas en Alicante ${ }^{19}$. Allí tuvo un lance con otro canónigo a raíz de los naipes, en que era un tahúr contrariamente a lo dispuesto por la legislación diocesana ${ }^{20}$. El suceso habría ocurrido del siguiente modo:

una noche, en cassa del canónigo Thomás Gironés, entre otras perçonas que acuden a jugar a los naypes, suçedió que el canónigo don Joseph Llop se allava delante con quatro o seys reales de a ocho. Dijo en alta vos: ¿ Ay quién quiera jugar este dinero a carseta o a pintas? Y como nadie le respondió, díjole al dicho canónigo Gironés, que se estava paseando por el quarto: ; Canónigo, ven y jugaremos los dos!. Y dicho

16. Archivo de la Catedral de Orihuela[=ACO]. Lib. 882 Acuerdos Capitulares (16721691), ff. $375 \mathrm{v}-378 \mathrm{v}$.

17. ACA. Consejo de Aragón. Leg. 686, doc. 63/115.

18. La fecha del documento, 1665. ACA. Consejo de Aragón. Leg. 915, doc. 3/1. Fue editado en Callado, 2014:179-185.

19. ACA. Consejo de Aragón. Leg. 686, doc. 63/3.

20. Así lo había confirmado el último sínodo celebrado en 1663, para los juegos de cartas y otros practicados por muchos clérigos, pues «notables son los inconvenientes que se siguen de los juegos, pues se pierde en ellos no solo la hacienda, pero muchas vezes el alma». Sinodo oriolana tercera. Murcia [s. a.], cap. XVI Del gobierno de los eclesiásticos y ministros de Dios, 80-81.

Ediciones Universidad de Salamanca / అ@@ Stud. his., H. ${ }^{a}$ mod., 42, n. 1 (2020), pp. 329-349 
EMILIO CALLADO ESTELA

LOS DESÓRDENES DEL CANÓNIGO DE LA CATEDRAL DE ORIHUELA JOSÉ LLOP. REFORMA, DELITOS Y CASTIGO EN EL SIGLO XVII

canónigo Gironés le respondió: No quiero jugar. Y dicho canónigo Llop, instándole a que jugasse. Respondió dicho Gironés: No quiero jugar, porque quiero guardar este dinero para regalar una comedianta. A que respondió dicho canónigo Llop y levantándose de la messa: ; También yo quiero éstos para regalar un pilón!. Y entre los dos tuvieron diferentes y graves palabras ${ }^{21}$.

No era otra la tal actriz que Teresa la Castañeda, de la compañía teatral por entonces en la ciudad y con la que José Llop mantenía un idilio, al parecer. No debía de ocultarlo mucho el canónigo, por cuanto llevado por los celos interrumpió una de las representaciones para subir al escenario de la corrala y abofetear públicamente a su amante...22

Hasta aquí llegó la paciencia del prelado Antonino Sánchez de Castellar. El 30 de abril del mismo año 1681 -con la concurrencia forzada de los conjudices catedralicios Jerónimo Fábregues y Pedro Antonio Roca- citaba judicialmente a Llop. En menos de tres días, compareció éste en el palacio episcopal de Orihuela. Quedaría bajo arresto provisional en una casa de la calle Rosell, so pena de 1000 libras en caso de contravención, mientras se esclarecían los excesos imputados a través del interrogatorio a una decena de testigos ${ }^{23}$.

Las declaraciones convencieron al obispo de la responsabilidad del prebendado, a quien sin sustanciársele proceso ninguno prohibió el 28 de mayo regresar a Alicante. El interesado apeló de inmediato contra este mandato, solicitando permiso al menos para «traher las alaxas que tiene en dicha ciudad para poner su cassa en ésta y estar con la desençia que permite su estado». Un mes exacto le concedería la mitra a tal fin. Eso sí, con prohibición expresa de acercarse en cualquier circunstancia al convento de la Sangre, cuyas monjas habían empezado a tapiar su terraza lindera con el domicilio de Jacques Llop por orden del monarca, quedando avalado así el proceder de Sánchez de Castellar ${ }^{24}$.

Lo impensable volvería a suceder cuando José Llop no volviera a Orihuela dentro del plazo establecido, mientras perseveraba por si fuera poco en las habituales demasías al lado de su hermano Pompeyo, para disgusto del ordinario. En defensa de éste y su tesón por la reforma del clero, salió el gobernador de Alicante don Francisco Guerau y Ciurana, con carta a la corona el 24 de agosto. En ella, cargaría las tintas no sólo sobre nuestro protagonista, sino también en quienes con él contemporizaban, muy particulamente el cabildo, al que convendría apercibir cuanto antes:

21. ACA. Consejo de Aragón. Leg. 686, doc. 63/22.

22. Sobre el teatro en Alicante véase Irles, 2000.

23. Recogidos entre el 22 y el 23 de mayo. ACA. Consejo de Aragón. Leg. 686, doc. 63/22.

24. ACA. Consejo de Aragón. Leg. 686, doc. 63/2. 
Don Joseph Llop ha venido acá adonde no pareze nada mejorado, teniendo barias pendençias por el juego, dando bofetadas a las comediantas y otros escándalos muy indignos de los ávitos de san Pedro. Éstos, señor, son los puríssimos ánimos de este canónigo y los deseos infructuossos del señor obispo, que lo serán mientras los conjúdizes concurran a la punisión de su collega pareze que obligados con carta del rey obrarían con mayor resoluzión ${ }^{25}$.

Dicho y hecho, el 15 de septiembre y en aras de la pacificación del reino Carlos II exigía a los jueces capitulares un castigo ejemplar para el canónigo Llop, «condigno a su repetida incorrección [y] para que sirva de escarmiento a otros ecclesiásticos que no viven con la atención que pide su estado» ${ }^{26}$.

Precisamente, dos de estos clérigos aludidos por el gobernador, irrumpirían en el palacio episcopal de Orihuela durante la medianoche del 4 de octubre para ajustar cuentas con su inquilino, a quien responsabilizaban de las últimas órdenes reales, y por tanto de menoscabo a la jurisdicción privilegiada de la Iglesia. Quiso el destino que Antonino Sánchez de Castellar se hallara fuera, de visita pastoral. Claro que su provisor allí presente, Pedro Juan Espí, padecería en carne propia la agresión, perdiendo una oreja a manos de los asaltantes armados con un trinchete de zapatero ${ }^{27}$.

No se hizo esperar la correspondiente denuncia de los hechos por parte del obispo, para cuya dignidad maltrecha exigió un desagravio a la altura de las circunstancias, empezando por el escarmiento de los culpables. Éranlo ni más ni menos -según las primeras investigaciones- los hermanos Llop, «hombres uno y otro ociosos, altivos, inquietos, jactanciosos $[\mathrm{y}]$ de maliçiosas costumbres» ${ }^{28}$. Contra ellos habían jurado venganza los parientes de su última víctima, temiéndose ahora un enfrentamiento que podía hacer saltar en pedazos un orden público tan frágil en el sur del reino de Valencia (García Martínez, 1991: 201ss).

Eso mismo debía pensar el gobernador de Alicante, que harto de la incorregibilidad de José, también ahora de Pompeyo, recomendó al monarca su inmediata expulsión del territorio, «con gran silenzio y resoluzión, porque no se ponga[n] en fuga para alterar toda esta provincia» ${ }^{29}$. El mejor modo de hacerlo, a través de la denominada potestad económica, tan recurrente durante las últimas décadas y que facultaba a la corona para proceder por vía extrajudicial contra cualquier súbdito implicado en graves crímenes, independientemente de su condición seglar

25. ACA. Consejo de Aragón. Leg. 686, doc. 63/4.

26. ACA. Consejo de Aragón. Leg. 686, doc. 63/7.

27. ACA. Consejo de Aragón. Leg. 686, doc. 63/115.

28. ACA. Consejo de Aragón. Leg. 686, doc. 63/44.

29. ACA. Consejo de Aragón. Leg. 686, doc. 63/47.

Ediciones Universidad de Salamanca / @®@@ Stud. his., H. ${ }^{a}$ mod., 42, n. 1 (2020), pp. 329-349 
EMILIO CALLADO ESTELA

LOS DESÓRDENES DEL CANÓNIGO DE LA CATEDRAL DE ORIHUELA JOSÉ LLOP REFORMA, DELITOS Y CASTIGO EN EL SIGLO XVII

o eclesiástica (Callado, 2002 y 2018; Fuertes, 2018). Opinión compartida por el Consejo de Aragón, según la consulta evacuada a este respecto ${ }^{30}$.

Carlos II había escuchado bastante. El 31 de octubre ordenaba al virrey de Valencia don Rodrigo Manuel Fernández Manrique de Lara, conde de Aguilar, servirse de tan excepcional procedimiento para deshacerse de canónigo y beneficiado, con el beneplácito de la mitra. Su detención a manos de ministros de la Real Audiencia, en Orihuela y Alicante, respectivamente, el 7 de noviembre, así como el posterior encarcelamiento de ambos en las cárceles reales de esta última ciudad, motivaron la protesta del cabildo orcelitano en defensa de la jurisdicción eclesiástica, cuyo máximo garante en la diócesis, es decir el obispo, había hecho dejación de la misma. Ello no impediría, cinco días después, el traslado de los reos-esposados y con escolta armada- hasta la capital del Turia, donde se les embarcó para los presidios de África ${ }^{31}$. En concreto, a Larache José y a Ceuta Pompeyo, destinos para algunos de los peores criminales de toda la Monarquía (García Figueras, 1973; Martínez Ruiz et alii, 2016).

Arreciándole las críticas capitulares por inacción frente a la actuación del banco regio, Antonino Sánchez de Castellar se ratificaría ante el monarca de cuanto había obrado tras el atentado contra su secretario:

Me a parecido no impedir al conde de Aguilar [...] la equonómica, de que le a parecido valerse para la prissión de dicho canónigo Loup, no porque a estar debaxo de mi jurisdicción solamente no le diera el condigno castigo [...], sino es porque viendo la remissión de mis adjuntos, que en más de un mes que sucedió dicho caso no an echo la más leve diligencia para la averigüación ni prissión de dicho Loup, puedo recelar que no lo harían en adelante. A esto se a opuesto el cabildo de dicha yglesia, pidiéndole a mi vicario general [...] procediesse contra los ministros de vuestra magestad con censuras y demás declaratorias. A que respondiendo dicho vicario tenía instrucción mía para no hazerlo, a imbiado dicho cabildo un canónigo para que supplique a vuestra magestad tenga por bien aya valido la económica para la prissión; mas que para el castigo le dexe vuestra magestad a los conjudices, que le darán el condigno a sus delitos.

A finales de noviembre el acoso contra el prelado llegaría a extremos inimaginables cuando, revestido y en plena celebración litúrgica en el convento de las capuchinas de Alicante, el cabildo le intimara un protesto (Cortés, 2018). En él, se le exhortó a proceder con censuras canónicas contra los ministros reales implicados en el arresto, encarcelamiento y traslado de los hermanos Llop, reclamándoles su inmediata restitución a la Iglesia, de la que eran súbditos y cuyo privilegium fori les

30. ACA. Consejo de Aragón. Leg. 686, docs. 63/49-63/50.

31. ACA. Consejo de Aragón. Leg. 686, doc. 63/13.

Ediciones Universidad de Salamanca / అ@@ Stud. his., H. ${ }^{a}$ mod., 42, n. 1 (2020), pp. 329-349 
EMILIO CALLADO ESTELA

LOS DESÓRDENES DEL CANÓNIGO DE LA CATEDRAL DE ORIHUELA JOSÉ LLOP. REFORMA, DELITOS Y CASTIGO EN EL SIGLO XVII

amparaba $^{32}$. Lejos de avenirse a semejante pretensión, Sánchez de Castellar volvería a depositar su confianza en el soberano:

Y aunque el cabildo de mi santa iglesia haga algún movimiento, que ya es ordinario haçerles contra los obispos y mui de la cathólica grandeza de vuestra magestad amparar a los prelados como echuras de la real elección, confío en vuestra magestad les ha de mandar templar y que se tengan en los límites de la racón y veneraçión que deven a su prelado ${ }^{33}$.

Para entonces, los clérigos represaliados habrían llegado ya a su confinamiento ${ }^{34}$. En el caso de José Llop sustituido sobre la marcha por el Peñón de Vélez de la Gomera, como consecuencia de las dificultades de navegación que la ruta hasta Larache ofrecía durante esta época del año ${ }^{35}$.

La noticia exasperó todavía más el ánimo de los canónigos de Orihuela, cuya irritación canalizaron a través de un memorial impreso que su agente en Madrid entregaría al soberano a comienzos de 1682, «con harto sentimiento de todo el clero eclesiástico, que representa este cabildo, y muda suspensión del estado, que advierte dolorido su inmunidad, vulnerada y perturbada mira la exempción de sus capitulares $[\mathrm{y}]$ todos ilessa notoriamente la jusrisdicción de sus adjuntos». No había más responsable de ello que el obispo, movido por siniestras maquinaciones en su desprecio sin precedentes hacia la inmunidad eclesiástica en la persona de José Llop, chivo expiatorio de los planes episcopales para deshacerse del capítulo catedralicio en el gobierno diocesano. De lo contrario, nadie entendía el ensañamiento con este clérigo de buena familia, vilipendiado a la vista de todos por el último crimen que se le atribuía, «como si fuera el más enorme assassino y fautor o receptor de quadrilleros». Y ello sin proceso ni juicio previo, pues

el obispo se ha apartado del curso ordinario de estas cuasas por aver concebido alguna desconfiança del cabildo, [aunque] no le han dado los conjudices el menor fundamento para ello, pues siendo proprio del obispo o de su provisor el convocarlos quando algún capitular ha delinquido, assí para passar a la averigüaçión y probança del delito, como también para proçeder al castigo, imponiendo al reo su merecida pena, no les han convocado sobre el nuevo delito que al canónigo Loup se le ha inputado, siendo assí que la vez que fueron convocados sobre el crimen

32. ACA. Consejo de Aragón. Leg. 686, doc. 63/16.

33. ACA. Consejo de Aragón. Leg. 686, doc. 63/15.

34. ACA. Consejo de Aragón. Leg. 686, doc. 63/36. A 298 libras, 17 sueldos y 9 dineros ascendió el coste total de la travesía, para cuya amortización -dada la estrechez de las arcas reales- se emplearía el presupuesto sobrante del año anterior ya que la lugartenencia general del reino de Valencia no había gastado todavía la partida de correos y barcas. ACA. Consejo de Aragón. Leg. 686, doc. 63/36.

35. ACA. Consejo de Aragón. Leg. 686, docs. 63/21 y 63/35.

Ediciones Universidad de Salamanca / అ@@ Stud. his., H. ${ }^{a}$ mod., 42, n. 1 (2020), pp. 329-349 
de aver puesto las manos en una comedianta por el abril passado no se negaron a diligencia alguna, que se jusgó importante y por el mes de mayo votaron concordes con el obispo la sentencia, que fue desterrarle de Alicante, donde se dixo cometió el delito, sin aver precedido ni aún semiplena prueba de aquel delicto ${ }^{36}$

¿Cómo entonces, sin dirimirse la responsabilidad penal del canónigo por la vía judicial ordinaria de la Iglesia, se había pasado a mayores, con el recurso a la potestad económica por parte de la corona, que en absoluto cuestionaba el cabildo, siempre y cuando concurrieran las condiciones necesarias para su empleo? Entre tales, la omisión o descuido de los jueces competentes, que no era el caso ahora ni nunca en Orihuela, como siempre habían demostrado los canónigos -y avalado el Tribunal de la Rota romana con sucesivas declaraciones- desde la erección de su sede hacía ya más de un siglo, haciendo cumplir la ley del lado de la mitra y ésta con ellos ${ }^{37}$.

\section{INTERVENCIÓN DE LA CONGREGACIÓN DE LAS IGLESIAS DE CASTILLA Y LEÓN, EL NUNCIO Y LA SANTA SEDE}

En solidaridad con los prebendados de Orihuela, otros cleros catedralicios de la Monarquía harían llegar su malestar a Carlos II, paradójicamente ninguno de la Corona de Aragón. El vejamen padecido por la inmunidad de la Iglesia en el reino de Valencia merecía, a juicio de los querellantes, una rápida satisfacción y la promesa de no repetirse en el futuro, ni allí ni en ninguna parte, preservándose así tanto los derechos eclesiásticos como las regalías de la corona. Petitorias en este sentido llegaron a la corte desde Andalucía, con Granada y Jaén al frente. Cuenca, Segovia, Ciudad Rodrigo y Plasencia lo harían en representación castellana. Como Oviedo o Lugo entre los rincones más septentrionales de la Península ${ }^{38}$.

No resulta extraño, pues, que acabara tomando cartas en el asunto la Congregación de las Iglesias de Castilla y León, organismo de carácter corporativo que reunía a las treinta y seis diócesis del lugar con la finalidad de defender mancomunadamente los privilegios del estamento eclesiástico y negociar las obligaciones fiscales de éste para con el estado (Martínez Ruiz, 1998: 91-92; Carpintero, 1993). En nombre de la misma, su procurador general y canónigo segoviano Alejandro Ortiz de Valdés, se erigió en defensor de las sedes hermanas catalanoaragonesas, aún fuera de su jurisdicción. El 21 de enero condenaba sin ambages al obispo de Orihuela por permitir innecesariamente tamaño atropello contra el cuerpo de Cristo. No obstante, todavía podía deshacer el entuerto suscribiendo el clamor general del clero patrio para que

36. ACA. Consejo de Aragón. Leg. 686, doc. 63/31.

37. ACA. Consejo de Aragón. Leg. 686, doc. 63/32.

38. Los citados memoriales en ACA. Consejo de Aragón. Leg. 686, s. d.

Ediciones Universidad de Salamanca / అ@@ Stud. his., H. ${ }^{a}$ mod., 42, n. 1 (2020), pp. 329-349 
José Llop regresara de África junto a su hermano, fuera juzgado por las instancias competentes y se le castigara si así lo mereciere ${ }^{39}$.

Antonino Sánchez de Castellar se revolvió contra tales acusaciones en un pliego de descargo, con el cual volvió a recriminar la condescendencia del cabildo en esta causa, «quando deviera ponerme la espada en la mano para que cortase el miembro podrido de su mesmo cuerpo porque no se ynficionase». Por eso él había recurrido finalmente al rey, con la esperanza de restablecer la paz en su Iglesia. De la corona dependía ahora la suerte del reo, no de la mitra:

Si por este camino pretenden annular la prisión -escribió a Carlos II- las han de haver con vuestra magestad, que yo soy vasallo primero que obispo y en lo que no infrinje los muros de la inmunidad eclesiástica y esplendor de la mitra [...] devo obedeçerle como es raçón. $\mathrm{Y}$ en este caso, que aún sin mi consentimiento puede obrar vuestra magestad, no sé yo en qué puede perjudicar la prisión este, que solo he dado porque no se turbase mi obispado con çensuras y se vejassen los ministros de vuestra magestad que havían executado un acto en desagravio de la Yglesia, del estado saçerdotal, de la mesma immunidad y mío tan justificado como ha sido ${ }^{40}$

Las dimensiones adquiridas por el asunto empezaban a preocupar seriamente al Consejo de Aragón. Hasta el extremo de plantear al monarca el traslado a Madrid de ambos reos -siempre con fianzas familiares que aseguraran su confinamientono tanto por hallarse ya rehabilitados, según las últimas informaciones, como para apaciguar la crispación existente entre las Iglesias hispánicas a raíz de la aplicación de la potestad económica ${ }^{41}$.

Así lo haría público el monarca a comienzos de marzo, sin lograr contentar en absoluto al capítulo orcelitano, empeñado en que solo la restitución de los Llop a la diócesis para su procesamiento podía subsanar cuantos perjuicios se habían ocasionado a la jurisdicción eclesiástica. Y ello sin prendas económicas a cambio, que «por la pobreza del padre y deudos no hay forma para darlas» ${ }^{42}$.

El tono de los canónigos contrarió al Consejo de Aragón, que durante los meses sucesivos insistió al monarca en no permitir bajo ningún concepto el regreso al reino de Valencia de José y Pompeyo, manteniéndose en cualquier caso la exigencia de las fianzas, por hallarse Jacques Llop entre los comerciantes más pudientes y acaudalados de Alicante ${ }^{43}$.

39. ACA. Consejo de Aragón. Leg. 686, doc. 63/32.

40. ACA. Consejo de Aragón. Leg. 686, doc. 63/24.

41. ACA. Consejo de Aragón. Leg. 686, doc. 63/43.

42. ACA. Consejo de Aragón. Leg. 686, doc. 63/57.

43. ACA. Consejo de Aragón. Leg. 686, docs. 63/55 y 63/56. Extremo confirmado por las destacadas cantidades que éste pagaría en concepto de derechos viejos y nuevos del General, un total de 1561 libras, 2 sueldos y 2 dineros (Martínez Ruiz y Gauci, 2008: 67).

Ediciones Universidad de Salamanca / 요 Stud. his., H. ${ }^{a}$ mod., 42, n. 1 (2020), pp. 329-349 
EMILIO CALLADO ESTELA

LOS DESÓRDENES DEL CANÓNIGO DE LA CATEDRAL DE ORIHUELA JOSÉ LLOP. REFORMA, DELITOS Y CASTIGO EN EL SIGLO XVII

Sería entonces cuando el cabildo de Orihuela se echara en brazos del cardenal Savo Millini. Más de un lustro al frente de la nunciatura española llevaba este diplomático, conocido por sus dotes negociadoras y tendencia natural a la componenda. Pero tanto o más, llegada la ocasión, por su energía infatigable en pedir satisfacción para los derechos y privilegios de la Iglesia lesos por cualquier razón, la inmunidad muy especialmente. Lo había demostrado en la corte, a cuenta de la prisión del favorito don Fernando de Valenzuela; en Mallorca, contra la Real Audiencia; y en Valencia, a raíz de la ejecución sumaria del agustino bandolero fray Facundo Ribera, que no hacía mucho había costado el puesto al entonces virrey duque de Veragua (Marqués, 1979-1980 y 1981-1982; Vatican, 2001).

Era previsible, por tanto, que el nuncio se pusiera de parte de los canónigos orcelitanos, cuya causa amparó en la Sagrada Congregación de la Inmunidad, erigida décadas atrás por Urbano VIII, precisamente, para ocuparse de la defensa de ésta donde quiera que se cuestionara (Moroni, 1842: 206-211). De ella recibiría un breve el obispo Sánchez de Castellar, en enero de 1683, prescribiéndosele «proceda contra los ministros reales que prendieron al canónigo Llop y que, puesto este en sus cárçeles, proçeda judicialmente contra él si le hallare culpado» ${ }^{44}$.

La amonestación dejó tocado al prelado, que sin saber cómo proceder ni a quién recurrir buscaría protección en el rey, a quien confesó el 7 de febrero:

el grave desconsuelo con que devo quedar, haviendo entendido siempre que lo que se practicó el año passado con el canónigo Joseph Loup fue mui conforme al grande y cristiano zelo de vuestra magerstad como hijo de la Iglesia y en la parte que a mí

44. Decía así el documento original latino: «Illustri et admodum reverendo domino uti frater. Inter episcoporum solicitudines ea debet esse praecipua, ut ecclesiastica iurisdictio a laycorum incursibus servetur incolumis quod ne debito frustretur effectu innumeris fere conciliis apostolicis ve sancionibus districti eisdem praecipitur ut in re tam gravi sedulo current, contrariis quibuscunque ausibus congruis presidiis obviare. Et cum in hac Sacra Congregatione Inmunitatis Ecclesia de amplitudine tua aliter audiatur, quod nempe propii muneris obliti canonicum Josephum Loup authoritate laicali carceratum nedum non vindicaveris, sed iurisdictionem ecclesiasticam per laicos ipsos pesundatam reintegrari neglexeris; eminentissimi patres hanc tui incuriam aegreferentes, et ne secularium indicum presumptuosa temeritas excrescat, imo quodcunque scandalum de super ob ortum de catholicorum mentibus deleatur, ordinariam authoritatem. A. I. duxerunt excitandam, ut super his omnibus (prout expedit) solicite provideas, et curiam secularem ad Ecclesiae iurisdictionis reintegrationem per censuras ecclesiasticas (appelatione remota) compescas. Ipsum vero canonicum inferis tua curia redactum (si de crimine resus existat) indicio tuo et duorum de gremio istius capituli iuridice supponas ad formam Sancti Concilii Tridentini, atque laudi inter istam ecclesiam et canonicos ab Hispaniarum apostolico nuntio (ut asseritur) promulgati. Monemus A. I. ut deinceps pro defensione immunitatis, libertatis et iurisdictionis Ecclesiae (prout pastorale munus exquirit) sedulo satagas, officium tuum cures et exequaris, ac praesentis Sanctae Congregationis litteras quam primum explevisse certiores. Vale Romae, 3 nonas iannarii». ACA. Consejo de Aragón. Leg. 686, doc. 63/62.

Ediciones Universidad de Salamanca / @®@@ Stud. his., H. ${ }^{a}$ mod., 42, n. 1 (2020), pp. 329-349 
EMILIO CALLADO ESTELA

LOS DESÓRDENES DEL CANÓNIGO DE LA CATEDRAL DE ORIHUELA JOSÉ LLOP. REFORMA, DELITOS Y CASTIGO EN EL SIGLO XVII

me tocó sin haver contravenido en un ápice a la immunidad ecclesiástica, de que daré satisfación siendo verdad quanto en lo concerniente a este negocio tengo escrito a vuestra magestad y al Supremo Consejo de Aragón y manifiesta impostura quanto havía escrito mi cabildo en contrario a Roma, donde me expressa el nuncio de su santidad ha recurrido para que emanase esta carta ${ }^{45}$.

En auxilio de Antonino Sánchez de Castellar salió el lugarteniente general del reino de Valencia conde de Aguilar, exonerándole de cualquier negligencia en su proceder. Como súbdito fiel de la corona, había obrado cuanto se esperaba de él en un lance tal, por encima de la jurisdicción eclesiástica, en preservación del orden de la república y con respeto a la potestad económica. Lo contrario, le habría supuesto incurrir en idéntico castigo al del canónigo José Llop ${ }^{46}$.

En ello coincidió el Consejo de Aragón, cuyo criterio acabaría prevaleciendo en la decisión final de Carlos $\mathrm{II}^{47}$. Efectivamente, el rey cerró filas en torno al ordinario, al que pidió dejar en suspenso la ejecución del último breve sin innovar nada en esta materia hasta más aviso. Por su parte, se comprometía a llamar a capítulo al nuncio para que transmitiera a Roma de primera mano la versión de los hechos que daba la razón a Sánchez de Castellar, evitándole de esta forma nuevos reproches por parte de la Sagrada Congregación de la Inmunidad ${ }^{48}$.

De poco sirvió por ahora el espaldarazo de la corona a la mitra, a juzgar por las maniobras del cabildo de Orihuela en la Santa Sede a través de su agente en aquella corte, el canónigo Vicente Sisternes. El 6 de abril se hacía eco de estas el obispo de Orihuela, temiéndose otro inminente dictamen apostólico en su contra. Acaso había llegado el momento de que la embajada de España ante Inocencio XI -a cargo provisionalmente de Bernaldo de Quirós, por la reciente promoción al virreinato de Nápoles del marqués del Carpio- tratara del asunto con el pontífice, pues «no pudiendo yo hazer parte alguna en este negocio puedo reçelar con mucho fundamento se me notifique algún nuevo mandamiento de la Sagrada Congregación» ${ }^{49}$.

Las sospechas del prelado cobraron fuerza a lo largo de aquel verano, con reiteradas peticiones de amparo al monarca mientras sus relaciones con el capítulo catedralicio seguían deteriorándose a un ritmo inquietante $e^{50}$. El 2 de octubre participó al secretario del Consejo de Aragón, Francisco Dalmao y Casanate, su confianza en

45. ACA. Consejo de Aragón. Leg. 686, doc. 63/62. En los mismos términos, aunque en diferente fecha, escribió también el ordinario al Consejo de Aragón. ACA. Consejo de Aragón. Leg. 686, doc. 63/65.

46. ACA. Consejo de Aragón. Leg. 686, doc. 63/63.

47. ACA. Consejo de Aragón. Leg. 686, doc. 63/68.

48. ACA. Consejo de Aragón. Leg. 686, doc. 63/108.

49. ACA. Consejo de Aragón. Leg. 686, doc. 63/73. A propósito de la embajada española en Roma durante esta época, véase Lefèvre, 1936; Ochoa, 2006; Barrio, 2009.

50. ACA. Consejo de Aragón. Leg. 686, docs. 63/84 y 63/97.

Ediciones Universidad de Salamanca / @®@@ Stud. his., H. ${ }^{a}$ mod., 42, n. 1 (2020), pp. 329-349 
EMILIO CALLADO ESTELA

LOS DESÓRDENES DEL CANÓNIGO DE LA CATEDRAL DE ORIHUELA JOSÉ LLOP. REFORMA, DELITOS Y CASTIGO EN EL SIGLO XVII

Savo Millini para contrarrestar la obstinación de los canónigos orcelitanos, cuyas gestiones estaban desangrando las arcas de la iglesia mayor:

Presumo, con mucho fundamento, que [el breve] le detiene el señor cardenal nunçio para representar a su santidad, por medio de dicha Sagrada Congregaçión, el juiçio que haçe desta materia, passando sus buenos ofiçios para que quede en silençio lo obrado. Y haviendo tenido mi cabildo copia del despacho de Roma, por medio del canónigo don Viçente Sisternes, que agençia allá este negoçio y no viendo efeto alguno de la orden de la Sagrada Congregaçión, esfuerçan nuebamente sus diligençias por el mismo medio del canónigo Sisternes, a quien remiten cantidad de dinero y creo también haçen presente en esta santa iglesia [de Orihuela] por estas agendas y porque imbiándole allá tan considerables socorros, se puede presumir tome este negocio en otro tiempo diferente estado ${ }^{51}$.

El asunto fue debatido en el plenario del Consejo de Aragón, resolviéndose ahora sí que el apoderado de la embajada española ante la Santa Sede contrarrestara las informaciones capitulares hechas llegar al papa con cuantas explicaciones fueran menester para suspender cualquier declaración pontificia ${ }^{52}$.

Esta intervención alejaría temporalmente del horizonte no solo la posibilidad de nuevos breves, sino también toda represalia contra Antonino Sánchez de Castellar. No menos quizá el hecho de que José y Pompeyo Llop - previa libranza de cuatro mil libras en concepto de fianza- abandonaran pronto su encierro africano, regresando a la Península en fecha imprecisa. Mientras el primero tomaba casa en la corte, el segundo se dedicó de momento al servicio militar. En mayo de 1684 ambos hermanos lograban poner en manos de Carlos II un suplicatorio para poder regresar al reino de Valencia. Se dolieron en él de continuar padeciendo indecibles penalidades por un delito jámás perpetrado ni probado, que además de tenerlos fuera de casa durante casi tres años había traído la desgracia a su familia. Porque, al descrédito reputacional, debía sumarse la ruina económica de mantenérseles mes tras mes, privados uno y otro de las rentas correspondientes a sus prebendas eclesiásticas ${ }^{53}$. De ello daría fe el principal afectado, Jacques Llop, con un escrito similar al de sus hijos, elevado en este caso al Consejo de Aragón ${ }^{54}$.

La sola posibilidad de que la corona pudiera dar crédito a estas lamentaciones puso en guardia al obispo de Orihuela, negando la mayor con tal de mantener fuera de la diócesis a los dos clérigos, cuya incorregibilidad a nadie escapaba, según advirtió al monarca:

51. ACA. Consejo de Aragón. Leg. 686, doc. 63/100.

52. ACA. Consejo de Aragón. Leg. 686, doc. 63/100.

53. ACA. Consejo de Aragón. Leg. 686, doc. 63/120.

54. ACA. Consejo de Aragón. Leg. 686, doc. 63/110.

Ediciones Universidad de Salamanca / అ@@ Stud. his., H. ${ }^{a}$ mod., 42, n. 1 (2020), pp. 329-349 
EMILIO CALLADO ESTELA

LOS DESÓRDENES DEL CANÓNIGO DE LA CATEDRAL DE ORIHUELA JOSÉ LLOP. REFORMA, DELITOS Y CASTIGO EN EL SIGLO XVII

Solamente devo poner lo dicho en la alta consideraçión de vuestra magestad para ponderar la incorregibilidad y pertinaçia en su mal proçeder de dicho canónigo Loup; y siendo ya tres las vezes que, sin embargo de los anteçedentes castigos y correcçiones a continuado en su depravado encono a los viçios, me pareçe se deve tener, según el Evangelio manda, como étnico y publicano. No solicitara, señor, su padre tanto como yo el que bolviera el canónigo Loup a cassa si tuviera esperanças de su corrección, porque soy su prelado y es de mi obligaçión esse cuidado. Mas como es de igual obligaçión de mi vigilancia y del serviçio de vuestra magestad el conservar la paz en este obispado, devo deçir a vuestra magestad quanto conviene el que no buelva dicho canónigo a esta ciudad [de Orihuela] asta tanto que sea tal su mudança que sea manssa oveja sin lo interior de lobo. En quanto Pompeyo Lop, por compañero de su hermano, traté de su castigo para que no se despeñasse en maldades. Tuve notícias después que está desterrado de una soltura que hizo en Zeuta ${ }^{55}$

Pese a todo, el nuevo virrey de Valencia don Pedro José de Silva, conde de Cifuentes, recibió orden desde Madrid para informar de las consecuencias de un hipotético retorno de los hermanos Llop. El noble recabaría antes la opinión al respecto de destacadas personalidades locales, entre ellas algunos «religiosos graves», para quienes José y Pompeyo podían ser algo relajados en su modo de vida, pero de ninguna manera los criminales que la mitra aseguraba. De modo que, una vez purgados sus pecados, nada impedía ya levantarles el destierro. Posibilidad finalmente suscrita por el lugarteniente general del reino ${ }^{56}$.

La idea fue descartada por el Consejo de Aragón, dispuesto como mucho a que canónigo y beneficiado volvieran a territorio valenciano. Pero de ninguna manera a Alicante ni a Orihuela, hasta demostrarse su plena rehabilitación, que por cierto sólo el ordinario estaba en condiciones de certificar. Entretanto, Jacques Llop se obligaría a entregar nuevas fianzas para garantizar el compromiso de sus hijos ${ }^{57}$.

Sin pronunciamiento del soberano durante los meses siguientes, se sucederían las súplicas de los dos principales interesados, así como sus familiares y deudos, cuyos contactos en la corte podrían explicar una nueva intervención de la Congregación de las Iglesias de Castilla y León en solidaridad con José y Pompeyo. Todo ello reforzaría las gestiones del cabildo orcelitano ante la Santa Sede, cuyo nuevo veredicto se conoció a principios de 1685 a través de la nunciatura, en pleno traspaso de poderes. Su todavía titular Savo Millini ordenó a Antonino Sánchez de Castellar deponer su actitud sin más réplica ni consulta. En este sentido, además de facilitar el retorno a casa de ambos clérigos, debería «observar y guardar los privilegios

55. ACA. Consejo de Aragón. Leg. 686, doc. 63/115.

56. ACA. Consejo de Aragón. Leg. 686, docs. 63/135-136.

57. ACA. Consejo de Aragón. Leg. 686, doc. 63/134.

Ediciones Universidad de Salamanca / అ@@ Stud. his., H. ${ }^{a}$ mod., 42, n. 1 (2020), pp. 329-349 
EMILIO CALLADO ESTELA

LOS DESÓRDENES DEL CANÓNIGO DE LA CATEDRAL DE ORIHUELA JOSÉ LLOP، REFORMA, DELITOS Y CASTIGO EN EL SIGLO XVII

apostólicos que tienen los jueçes adjuntos», en evitación de futuras lites con su capítulo catedralicio ${ }^{58}$.

\section{4. ¿FIN...?}

Cansado de una controversia que venía ocupándole desde comienzos de su pontificado hacía seis años, el obispo e Orihuela no resistió más. En respuesta a otra del canónigo Llop, prometiéndole obediencia, respondió en abril de 1685 como prueba de su buena voluntad:

Nunca se han visto apartadas de la voluntad y afecto con que amo a todos los capitulares de esta santa ygleçia los deseos de estimarles muy conforme lo mereçen. Y los que vuestra merçed me expressa en su carta de 24 del passado me aseguran muy gustosso de aplicarme a su cumplimiento, como también a las ocasiones que sucçedieran del consuelo de vuestra merced, cuya vida guarde Nuestro Señor en su graçia ${ }^{59}$

Este extremo justificaría el hecho de que el prelado se mostrara a partir de entonces un convencido defensor de la petición del principal de los reos, sus familiares y compañeros. Incluso a Carlos II llegó a plantearle lo siguiente el 25 de agosto:

Con ocasión de tener repetidas noticias de los vivos deseos que assisten al canónigo Joseph Loup de residir su prebenda en esta santa yglesia y de la mucha necessidad y pobressa que padeçe en esta corte, por no tener otros medios y haber sesado ya los que le ministraban sus padres, que se allan también muy faltos de recursos y con la confiança que se puede prometer de su emienda por lo que ha padecido en el tiempo que falta de esta ciudad [de Orihuela], passo a representar a vuestra magestad estas raçones para que, usando de su real clemencia, mande restituirle a dicha su yglesia, con lo qual se conseguirá el consuelo grande de sus padres y que tenga los medios que necesita para poder vivir con la desençia de su estado, que si no correspondiere en adelante a las obligaciones de él, siempre habrá lugar para el castigo, quedando yo siempre con la vigilancia que devo, assí de atender a sus operaçiones como de pasarlas a la noticia de vuestra magestad, quando no fuessen reguladas, para ocurrir al remedio que pidieren ${ }^{60}$

Decisivo resultó el cambio de parecer de la mitra en la decisión final adoptada por la corona con los hermanos Llop, cuyo regreso se autorizó transcurrido aquel mismo verano ${ }^{61}$.

58. ACA. Consejo de Aragón. Leg. 686, doc. 63/122.

59. ACA. Consejo de Aragón. Leg. 686, doc. 63/123.

60. ACA. Consejo de Aragón. Leg. 686, doc. 63/128.

61. ACA. Consejo de Aragón. Leg. 686, doc. 63/132-62/133.

Ediciones Universidad de Salamanca / అ@@ Stud. his., H. ${ }^{a}$ mod., 42, n. 1 (2020), pp. 329-349 
Poco sabemos de la suerte de ambos clérigos desde su reincorporación a las prebendas que les eran propias. Sobre Pompeyo, se haría el silencio más absoluto; a José, por el contrario, podría seguírsele el rastro a través de los libros de acuerdos del cabildo de Orihuela, donde su nombre aparece hasta comienzos de la nueva década ${ }^{62}$. Señal, tal vez, de que ninguno de ellos volvió a dar motivo suficiente para notárseles nuevamente por relapsos o instruírseles nuevos expedientes disciplinarios.

Cosa bien distinta es que Antonino Sánchez de Castellar renunciara a su firmeza con cuantos clérigos recalcitrantes amenazaran la reforma eclesiástica poniendo en riesgo la estabilidad de la diócesis. Sobre todo si de capitulares se trataba, modelo para el resto del clero secular. De ahí que, cuando en 1691 trascendiera el amancebamiento público del chantre de la seo Domingo Bru de Miralles, lograra contra este una orden de destierro por parte de la corona, pese al enésimo enfrentamiento que este recurso le supondría con su cabildo a cuenta de la jurisdicción eclesiástica otra vez puesta en entredicho al sur del reino de Valencia... ${ }^{63}$

En realidad, en todas partes, durante los últimos años de la centuria y a lo largo de la que estaba por venir. Porque episodios como los descritos seguirían revelando el grado de tensión y conflictividad existente en las Iglesias de la Monarquía entre obispos y capítulos catedralicios, buscando apoyos externos ya en el rey los primeros, ya en la Santa Sede los segundos, directamente o a través del nuncio. Los litigios, pues, continuaron sucediéndose prácticamente en idénticos términos a cuantos habían inaugurado la época postridentina, señal evidente de que el proceso de sujeción capitular al báculo episcopal pretendido por el concilio distaba todavía de ser una realidad.

\section{BIBLIOGRAFÍA}

Aldea Vaquero, Q. (1961). Iglesia y Estado en la España del siglo XVII (Ideario políticoeclesiástico). Miscelánea Comillas, 36, 1-125.

Arqués, A. (1966). Nobiliario alicantino. Alicante: Ayuntamiento de Alicante.

Barrio Gozalo, M. (2009). La embajada de España ante la corte de Roma en el siglo XVII. Ceremonial y práctica del buen gobierno. Studia Historica Historia Moderna, 31, 237-273.

Bibiloni Armengual, A. (1990). El comerç exterior de Mallorca. Homes, mercats i productes d'intercanvi, 1650 - 1720. Palma: El Tall.

Bustos Rodríguez, M. (1983). Un comerciante saboyano en el Cádiz de Carlos II. Las memorias de Raimundo Lantery, 1673 - 1700. Cádiz: Caja de Ahorros de Cádiz.

62. ACO. Lib. 882 Acuerdos Capitulares (1672-1691), ff. 474-476, y Lib. 883 Acuerdos Capitulares (1692-1707), ff. 18v y 34v-36v.

63. ACA. Consejo de Aragón. Leg. 688, docs. 73/1-73/20.

Ediciones Universidad de Salamanca / అ@@ Stud. his., H. ${ }^{a}$ mod., 42, n. 1 (2020), pp. 329-349 
EMILIO CALLADO ESTELA

LOS DESÓRDENES DEL CANÓNIGO DE LA CATEDRAL DE ORIHUELA JOSÉ LLOP. REFORMA, DELITOS Y CASTIGO EN EL SIGLO XVII

Callado Estela, E. (2001). Iglesia, poder y sociedad en el siglo XVII. El arzobispo de Valencia fray Isidoro Aliaga. Valencia: Biblioteca Valenciana.

Callado Estela, E. (2003a). Garrote a fray Facundo Ribera. La polémica ejecución de un fraile agustino en 1680. Anales Valentinos, 57, 95-119.

Callado Estela, E. (2001b). Inmunidad eclesiástica y delincuencia. Los arzobispos de Valencia y la pacificación del reino (1612 - 1699). Valencia: Biblioteca Valenciana.

Callado Estela, E. (2003). "Sínodos, fiestas y religiosidad popular en la Valencia del siglo XVII». En F. J. Aranda Pérez (Coord.), Ocio y vida cotidiana en el Mundo Hispánico en la Época Moderna. Sevilla: Universidad de Sevilla, 245-258.

Callado Estela, E. (2007). Por Dios y por el rey. El Inquisidor general fray Juan Tomás de Rocabertí. Valencia: Alfons el Magnànim.

Callado Estela, E. (2011). Tiempos de incienso y pólvora. El arzobispo fray Pedro de Urbina. Valencia: Biblioteca Valenciana.

Callado Estela, E. (2014). Mujeres en clausura. El convento de Santa María Magdalena de Valencia. Valencia: Universitat de València.

Callado Estela, E. (2018a). San Juan de Ribera, un obispo según el ideal de Trento. En A. Prosperi: Trento and Beyond. The Council, Other Powers, Others Cultures. Roma: Brépols, 191-208.

Callado Estela, E. (2018b). El taimado Caracol. Un fraile bandolero en la Valencia Barroca. En J. S. Amelang et alii (Eds.). Palacios, plazas, patíbulos. La sociedad española moderna entre el cambio y las resistencias. Valencia: Tirant lo Blanch, 247-257.

Callado Estela, E. (2019). Crisis y conflicto. El cabildo de la catedral de Valencia en el siglo XVII. Valencia: Tirant lo Blanch.

Candau Chacón, Ma . L. (1993). Los delitos y las penas en el mundo eclesiástico sevillano del XVIII. Sevilla: Diputación de Sevilla.

Cárcel Ortí, Ma . M. (1989). Relaciones sobre el estado de las diócesis valencianas I. Oribuela. Valencia: Generalitat Valenciana.

Carpintero Aguado, L. (1993). La Congregación del Clero de Castilla en el siglo XVII. Tesis doctoral inédita: Universidad Autónoma de Madrid.

Carrasco Rodríguez, A. (2001). La ciudad de Oribuela y el pleito del obispado en la Edad Moderna. Tesis doctoral inédita: Universidad de Alicante.

Casey, J. (1983). El reino de Valencia en el siglo XVII. Madrid: Siglo XXI.

Casey, J. (1988). Bandos y bandidos en la Valencia Moderna. En Homenatge al doctor Sebastià Garcia Martínez. Valencia: Generalitat Valenciana, I, 407-421.

Cereceda, F. (1944). El litigio de los cabildos y su repercusión en las relaciones con Roma (1551 - 1556). Razón y Fe, 130, 215-234.

Cortés Sempere, Ma . C. (2018). Historias de Alicante a través del claustro de las capuchinas. Siglos XVII - XXI. Alicante: Instituto Alicantino de Cultura Juan Gil Albert.

D’Aulnoy, M. C. (s. a.). Un viaje por España en 1679. Madrid.

Díaz Rodríguez, A. J. (2010). Cabildos catedralicios y clero capitular en el Antiguo Régimen: estado de la cuestión. Revista de Historiografía, 13, 82-89.

Ediciones Universidad de Salamanca / 요 Stud. his., H. ${ }^{a}$ mod., 42, n. 1 (2020), pp. 329-349 
EMILIO CALLADO ESTELA

LOS DESÓRDENES DEL CANÓNIGO DE LA CATEDRAL DE ORIHUELA JOSÉ LLOP. REFORMA, DELITOS Y CASTIGO EN EL SIGLO XVII

Domínguez Ortiz, A. (1973). Las clases privilegiadas en la España del Antiguo Régimen. Madrid: Istmo.

Echániz Martínez, B. (2017). Las monjas de la Sangre. Historias de vida en la modernidad alicantina. Tesis doctoral inédita: Universidad de Alicante.

Felipo Orts, A. (1988). El centralismo de nuevo cuño y la politica de Olivares en el País Valenciano. Valencia: Ayuntamiento de Valencia.

Felipo Orts, A. y Callado Estela, E. (2016). Entre la cátedra y el púlpito. Los pavordes de la Universidad de Valencia (siglos XVI-XVII). Valencia: Universitat de València.

Ferrero Micó, R. (1985). Bandosidades nobiliarias en Valencia durante la época foral. Saitabi, XXXV, 95-110.

Fuertes Broseta, M. (2018). Uso de la potestad económica y respuesta estamental. El aprisionamiento de Leandro Escales en el Peñón de los Vélez. En J. S. Amelang et alii (Eds.). Palacios, plazas, patíbulos. La sociedad española moderna entre el cambio y las resistencias. Valencia: Tirant lo Blanch, 234-245.

García Figueras, T. (1973). Larache, datos para su historia en el siglo XVII. Madrid: Instituto de Estudios Africanos - CSIC.

García Martínez, S. (1991). Valencia bajo Carlos II: Bandolerismo, reivindicaciones agrarias y servicios a la Monarquía. Valencia: Ayuntamiento de Villena.

Girard, A. (1934). Le commerce français à Seville et Cádiz au temps des Habsbourgs. Contribution à l'étude du commerce étrànger en Espagne aux XVI et XVII siécle. París-Burdeos: Boccard-Féret.

Goñi Gaztambide, J. (1975). Los cabildos españoles y la confirmación del Concilio de Trento. Annuarium Historiae Conciliorum, 7, 425-458.

Guía Marín, L. (1980). La Guerra de Cataluña y el bandolerismo valenciano (1640 - 1652). En $I^{\mathrm{er}}$ Colloque sur le Pays Valencien a l'époque moderne. Pau, 117-141.

Guía Marín, L. (1984). Dissidència política i repressió social al País Valencià a mitjan segle XVII. Saitabi, XXXIV, 105-124.

Guía Marín, L. (1994). Rebels i marginats en el segle XVII valencià. En La Segona Germania. Col-loqui Internacional. Valencia: Diputación de Valencia, 65-132.

Guía Marín, L. (2002). Dona, honor i bandolerisme: els desordres de l'Almirall d’Aragó en la València del segle XVII. Estudis, 28, 287-315.

Guía Marín, L. (2003). Bandoleros, rebeldes y marginados: Mateu Vicent Benet y las bandositats valencianas. En Banditismi mediterranei (secoli XVI - XVII). Cerdeña: Carocci, 87-106.

Irigoyen López, A. (2000). Entre el Cielo y la Tierra, entre la familia y la institución. El cabildo de la catedral de Murcia en el siglo XVII. Murcia: Universidad de Murcia.

Irles, E. (2000). Historia del Teatro en Alicante: tiempos prologales. Alicante: Ayuntamiento de Alicante.

Lefèvre, J. (1936). L'ambassade d'Espagne auprès du Saint Siège au XVII ${ }^{e}$ siècle». Bulletin de l'Institut Historique Belge de Rome, 17, 5-56.

Llorente de Pedro, P. A. (2007). La ciencia penitenciaria del Antiguo Régimen aplicada al presidio de Centa. Ceuta: UNED.

Ediciones Universidad de Salamanca / అ@@ Stud. his., H. ${ }^{a}$ mod., 42, n. 1 (2020), pp. 329-349 
EMILIO CALLADO ESTELA

LOS DESÓRDENES DEL CANÓNIGO DE LA CATEDRAL DE ORIHUELA JOSÉ LLOP. REFORMA, DELITOS Y CASTIGO EN EL SIGLO XVII

Marín Martínez, T. (1948). Primeras repercusiones tridentinas: el litigio de los cabildos españoles. Su proceso en la diócesis de Calahorra. Hispania Sacra, 1, 325-349.

Marqués, J. Ma . (1979 - 1980). Entre Madrid y Roma. La nunciatura de Madrid en 1675. Anthologica Annua, 26-27, 407-553.

Marqués, J. Ma . (1981 - 198). La Santa Sede y la España de Carlos II. La negociación del nuncio Millini 1675 - 1685. Anthologica Annua, 28-29, 259-262.

Martínez Ruiz, E. et alii (2016). Los presidios españoles norteafricanos en el siglo XVIII. Madrid: Ministerio de Defensa.

Martínez Ruiz, E. (Dir.) (1998). Diccionario de Historia Moderna de España. I La Iglesia. Madrid: Akal.

Martínez Ruiz, J. I. y Gauci, P. (2008). Mercaderes ingleses en Alicante en el siglo XVII. Estudio y edición de la correspondencia comercial de Ricard Houncell E Co.. Alicante: Universidad de Alicante.

Montojo Montojo, V. (2008). Los comerciantes de Alicante y Cartagena en la Guerra de Sucesión. Estudis, 34, 219-239.

Montojo Montojo, V. (2010a). El comercio de Cartagena y Alicante tras la Guerra de Sucesión. Espacio, tiempo y forma. Historia Moderna, 23, 203-226.

Montojo Montojo, V. (2010b). El comercio de Alicante a mitad del siglo XVII según los derechos y sisas locales de 1658 - 1662 y su predominio sobre el de Cartagena. Murgetana, 122, 43-66.

Moroni, G. (1842). Dizionario di erudizione storico-ecclesiastica da san Pietro sino ai nostri giorni. Venecia: Tipografia Emiliana.

Ochoa Brun, M. A. (2006). Historia de la diplomacia española. La Edad Barroca. Madrid: Biblioteca Diplomática Española.

Pérez Muñoz, I. (1992). Pecar, delinquir y castigar: el tribunal eclesiástico de Coria en los siglos XVI y XVII. Cáceres: Institución cultural El Brocense.

Revuelta González, M. (1973). Política religiosa de los liberales en el siglo XIX. Trienio Constitucional. Madrid: CSIC.

Sánchez González, R. (2000). Iglesia y sociedad en la Castilla Moderna. El cabildo catedralicio de la Sede Primada (siglo XVII). Toledo: Ayuntamiento de Toledo.

Sinodo oriolana tercera. Murcia, s. a.

Torremocha Hernández, M. (2007). El galanteo. Una práctica amorosa española vista desde Europa (siglo XVII). En Historia y género: imágenes y vivencias de mujeres en España y América (siglos XV-XVIII). Málaga: Universidad de Málaga, 169-200.

Urzainqui Sánchez, S. (2016). Bandidos y bandolerismo en la Valencia del siglo XVII: nuevas fuentes, nuevas perspectivas. Tesis doctoral inédita: Universitat de València.

Vatican, A. (2001). La nunciatura española bajo el reinado de Carlos II: Savo Millini (1675 - 1685). Cuadernos de Historia Moderna, 26, 131-147.

Vidal Tur, G. (1961). Un obispado español. El de Oribuela-Alicante. Alicante: Diputación de Alicante.

Ximeno, V. (1747 - 1749). Escritores del reyno de Valencia. Valencia: Esteban Dolz.

Ediciones Universidad de Salamanca / 요 Stud. his., H. ${ }^{a}$ mod., 42, n. 1 (2020), pp. 329-349 